\title{
Reversible pupillary miosis during a hyperglycaemic episode: case report
}

\author{
G. Boutros and M.S. Insler \\ Department of Ophthalmology, Tulane University, New Orleans, Louisiana, USA
}

\begin{abstract}
Summary. A young female patient presented with non-ketotic hyperglycaemia, pupillary miosis and clouding of consciousness. The initial blood glucose was $83.3 \mathrm{mmol} / 1$; there was no metabolic acidosis. After insulin therapy and improved diabetic control, pupillary function returned to normal. There
\end{abstract}

was no other associated somatic or autonomic nerve dysfunction.

Key words: Pupillary miosis, non-ketotic hyperglycaemia.
In recent years many authors have studied pupil size and motility in diabetic subjects [1-5]. Hreidarsson [4] concluded that the resting pupil size in darkness decreased with increasing duration of diabetes. This would place the abnormally small pupil as an integral part of the long-term diabetic syndrome. Metabolic derangement has also been associated with a markedly reduced ability to maintain miosis in continuous light [3].

Acute reversible pupillary changes have been described in Type 1 (insulin-dependent) diabetes during phases of poor metabolic control and redilation time was prolonged from 2.26 to $2.90 \mathrm{~s}$ [3]. These changes were related to diabetic control and may be analogous to the well established reversible functional change in the somatic neuro system in early diabetes. We report a patient showing acute reversible pupillary changes in the non-ketotic hyperglycaemic state.

\section{Case report}

A 34-year-old single black lady walked into the Emergency Department of the Touro Infirmary complaining of weakness, blurred vision and visual hallucinations for 3 days. An accurate history could not be obtained, but there appeared to be no history of polydypsia, polyuria, nausea, vomiting or weight loss. Her past history revealed that 18 months ago she had been treated for hypertension for 2 months with $20 \mathrm{mg}$ furosemide/day History obtained from her immediate family excluded previous diabetes, drug intake of any kind during the past year, or abnormal blood pressure readings within the past 18 months.

Her general physical examination upon admission demonstrated clouded sensorium and pinpoint pupils. Vital signs were: blood pressure: $130 / 95 \mathrm{mmHg}$; pulse rate: 78 beats $/ \mathrm{min}$; temperature: $37^{\circ} \mathrm{C}$; respirations: 16 breaths $/ \mathrm{min}$; height: $175 \mathrm{~cm}$; weight: $75 \mathrm{~kg}$.

Naloxone (1 $\mathrm{ml}$ ) was given intravenously with no effect. Laboratory results on admission included blood glucose: $83.3 \mathrm{mmol} / \mathrm{l}$; sodium: $139 \mathrm{mmol} / \mathrm{l}$; potassium: $3.6 \mathrm{mmol} / 1$; chloride: $76 \mathrm{mmol} / \mathrm{l}$; and carbon dioxide: $30 \mathrm{mmol} / 1$. Urinary analysis showed a specific gravity of 1.025 ; glucose $2+$; protein $1+$, but was negative for ketones.

The patient was admitted to the Intensive Care Unit and intravenous insulin treatment was started with a pump delivering $10 \mathrm{U}$ insulin $/ \mathrm{h}$, and the glucose value was estimated every $3 \mathrm{~h}$. On day 2 after admission, the patient required $40 \mathrm{U}$ insulin. Her biochemical picture had improved remarkably with a blood glucose level of $15.5 \mathrm{mmol} / 1$; there was no proteinuria and her creatinine clearance was $100 \mathrm{ml} / \mathrm{min}$. The patient's sensorium, however, remained clouded. Eye examination revealed the pupils to be equal and reactive to light with a diameter of $5 \mathrm{~mm}$.

The patient maintained a blood glucose level ranging from 11.11 to $15.00 \mathrm{mmol} / 1$ on $35 \mathrm{U}$ insulin/day over the first 3 days in hospital. Her insulin requirement dropped to $10 \mathrm{U} /$ day on days 4 and 5 of admission. On day 4 after admission, the patient's level of consciousness improved and she related that she was amnesic for 

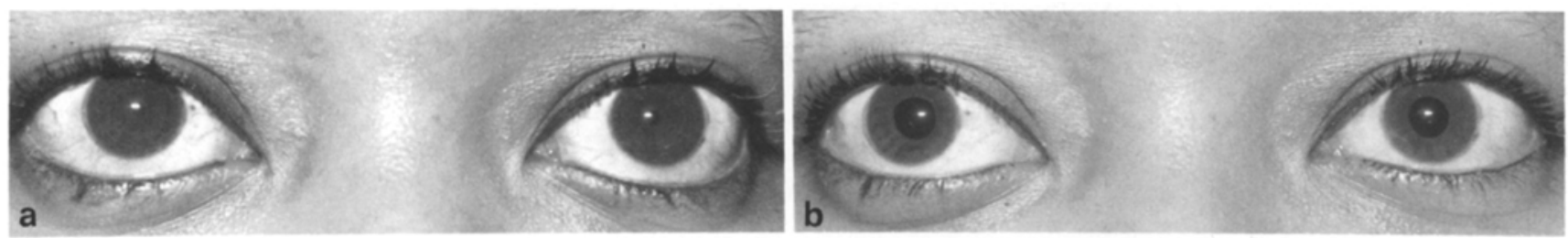

Fig. 1. a and b. The state of the pupils of a 34-year-old black lady with non-ketotic acute hyperglycaemia: a Pupillary miosis upon initial presentation; b pupils 1 day after onset of treatment

the past 3 days. The patient was discharged from hospital on $10 \mathrm{U}$ insulin/day after 8 days in hospital without the develpoment of complications. Her blood glucose level on discharge was $5.5 \mathrm{mmol} / \mathrm{l}$.

\section{Results}

The initial bedside clinical assessment revealed an uncorrected visual acuity of $20 / 40$ for each eye. Tension with a Schiotz tonometer (Storz, St. Louis, Missouri, USA) demonstrated intraocular pressures of 14 and 18 $\mathrm{mmHg}$ for the right and left eyes, respectively. No conjuctival injection was noted and the corneas were clear. Both pupils were miotic and measured $1 \mathrm{~mm}$ in diameter with questionable reaction to light (Fig. 1a). The severe miotic state of the pupils precluded clear documentation of the pupillary reaction to near, direct and concensual stimuli. The patient's accommodative status could not be assessed, but she did demonstrate 10 diopters of convergence to near stimuli. Her extraocular muscles had full motion with intact fields of gaze.

On day 2 after admission, her eye examination revealed pupil size to be equal, round and reactive to light with a diameter of $5 \mathrm{~mm}$ (Fig. $1 \mathrm{~b}$ ). Near, direct and consensual pupillary reflexes were normal and all eye versions were intact. Her visual acuity was $20 / 20$ in each eye and refraction revealed her eyes to be ametropic. Fundus examination was within normal limits.

\section{Discussion}

Focal neurological deficits in non-ketotic acute hyperglycaemia is a relatively recent concept first demonstrated in 1968 by Maccario [8]. He concluded that hyperglycaemia can cause metabolic derangements that could lead to focal somatic reversible neurological dysfunction. Pupillary changes could be present, but according to Maccario they were not reversible and therefore not related to the hyperglycaemia, but rather to long-standing diabetes.

Since that time, further reports on patients with nonketotic hyperglycaemia have suggested that the various focal neurological signs described might indicate brain stem dysfunction as well as autonomic nervous system disturbances. [3, 6-10]. Yet the first and only mention of reversible autonomic nervous system disturbances and specific pupillary changes were mentioned by Hreidarsson [3]. His report, however, involved short-term Type 1 diabetic patients in whom he documented reversible prolongation of redilation time with poor control. However, the miosis in these subjects was only moderate and could not be sustained. Our case report supports Hreidarsson's conclusion that reversible changes in the autonomic nervous system do occur with poor metabolic control.

\section{References}

1. Bryant CR (1980) Pupil motility in long-term diabetes. Diabetologia 18: 170-171

2. Hreidarsson AB (1979) Pupil motility in long-term diabetes. Diabetologia 17: 145-150

3. Hreidarsson AB (1981) Acute, reversible autonomic nervous system abnormalities in juvenile insulin-dependent diabetes. A pupillographic study. Diabetologia 20: 475-481

4. Hreidarsson AB (1981) Pupil size in insulin-dependent diabetes. Diabetes 31: 442-448

5. Smith SA, Smith SE (1983) Evidence for a neuropathic aetiology in the small pupil of diabetes mellitus. $\mathrm{Br} \mathrm{J}$ Ophthalmol 67: 89-93

6. Arieff A, Carroll H (1972) Nonketotic hypersmolar coma with hyperglycemia. Medicine (Baltimore) 51:73-94

7. Guisado R, Arieff A (1975) Neurologic manifestations of diabetic comas: correlation with biochemical alterations in the brain. Metabolism 24: 665-679

8. Maccario M (1968) Neurological dysfunction associated with nonketotic hyperglycaemia. Arch Neurol 19: 525-534

9. McCurdy D (1970) Hyperosmolar hyperglycemic nonketotic diabetic coma. Med Clin North Am 54: 683-699

10. Simon RP, Freedman DD (1980) Neurologic disorders of osmolar disorders. Geriatrics 35: 71-83

Received: 3 October 1983

and in revised form: 18 May 1984

Dr. George Boutros

Department of Ophthalmology

1430 Tulane Avenue

New Orleans, LA 70112

USA 